\title{
ALOKASI PENDAPATAN RUMAH TANGGA TENAGA KERJA WANITA YANG BERMIGRASI KE LUAR NEGERI DI KABUPATEN LOMBOK TIMUR
}

\author{
Luluk Fadliyanti $^{1}$, Ihsan Rois ${ }^{1}$, Baiq Saripta Wijimulawiani ${ }^{1}$ \\ ${ }^{1}$ Fakultas Ekonomi dan Bisnis, Universitas Mataram \\ *email korespondensi : fadliyanti@gmail.com
}

Info Artikel

ABSTRAK

\author{
Kata Kunci: \\ Tenaga kerja wanita, \\ Pendapatan, \\ Rumah tangga
}

\begin{abstract}
Penelitian ini bertujuan untuk menganalisis alokasi pendapatan tenaga kerja wanita yang berasal dari kabupaten Lombok Timur yang bermigrasi ke luar negeri, serta melihat faktor-faktor apa saja yang mempengaruhi pengeluaran pendapatan keluarga tenaga kerja wanita migran tersebut. Metode penelitian yang digunakan dalam penelitian ini adalah metode kuantitatif, dengan menggunakan alat analisis Seemingly Unrelated Regression (SUR). Hasilnya bahwa alokasi pengeluaran rumah tangga tenaga kerja wanita migran paling tinggi adalah untuk pengeluaran makanan yang dipengaruhi oleh jumlah anak usia 6-18 tahun dan jumlah anak usia 0-5 tahun. Selanjutnya diikuti oleh pengeluaran kebutuhan rumah tangga lainnya yang dipengaruhi oleh jumlah tanggungan keluarga dan jumlah anak usia 0-5 tahun, pengeluaran pendidikan dipengaruhi oleh jumlah anak usia 6-18 tahun dan pengeluaran kesehatan dipengaruhi oleh jumlah anak usia 0-5 tahun.
\end{abstract}

\section{Pendahuluan}

Migrasi internasional sebagai salah satu alternatif tenaga kerja wanita lokal untuk mencari pekerjaan di dalam menanggulangi pengangguran serta agar dapat keluar dari kemiskinan. Bardhan dan Udry (1999) menyebutkan bahwa migrasi merupakan salah satu strategi yang digunakan rumah tangga untuk menjamin kestabilan pendaptan mereka. Bryant (2005) menyebutkan bahwa pertumbuhan migrasi internasional di negara-negara selatan dan timur Asia berpengaruh secara signifikan terhadap anak-anak, sekita 3-6 juta anak dari Filipina yang ditinggalkan oleh orang tuanya bermigrasi ke luar negeri. Di Indonesia sekitar 1 juta anak yang juga ditinggalkan oleh orangtuanya bermigrasi ke luar negeri dan 0,5 juta anak dari Thailand yang juga mengalami hal yang sama.

Hasil remittance dari TKI Indonesia adalah tercatat pada tahun 2016 sejumlah US\$ 742 juta (Puslitfo BNP2TKI, 2017). Kesejahteraan keluarga yang ditinggalkan tenaga kerja migran meningkat secara signifikan dengan remittance yang di transfer (Quartey, 2006). Keterlibatan 
perempuan dalam ekonomi merupakan fenomena penting dalam era globalisasi. seiring dengan perkembangan migrasi, secara global tampaknya fenomena migrasi perempuan semakin mendominasi. Bagi wanita yang telah menikah angka partisipasi yang dialokasikan dalam pasar tenaga kerja akan dipengaruhi oleh faktor keluarga, tanggung-jawab utama merawat rumah dan mengasuh anak merupakan kendala untuk menentukan keputusan bekerja. Kondisi perekonomian keluarga dan tingkat pendidikan memberi pengaruh pada partisipasi wanita untuk bekerja baik bagi wanita yang sudah menikah maupun bagi wanita yang belum menikah.

Kabupaten Lombok Timur merupakan salah satu kabupaten yang berada di provinsi NTB yang merupakan kabupaten penyumbang tenaga kerja migran tertinggi di Indonesia (Puslitfo BNP2TKI, 2017)). Di kabupaten ini terdapat 5 (lima) kecamatan pengirim terbesar TKI yaitu Kecamatan Aikmel, Sakra Barat, Terara, Pringgabaya dan Keruak. Ketersediaan angkatan kerja yang sedemikian besar di kabupaten Lombok Timur juga dapat mendatangkan berbagai permasalahan bidang perekonomian, diantaranya adanya keterbatasan penciptaan lapangan kerja. Karena banyaknya tenaga kerja yang tidak terserap maka timbulnya banyak pengangguran terutama pada tenaga kerja yang mempunyai pendidikan rendah, sehingga hal tersebut berpengaruh langsung terhadap perekonomian keluarga, karena kurang tersedianya lapangan pekerjaan serta upah yang rendah sehingga tidak dapat memenuhi kebutuhan ekonomi, maka keluarga mengambil keputusan untuk mengirim anggota keluarga mereka untuk bekerja di luar negeri.

Pada level rumah-tangga keputusan untuk menjadi tenaga kerja wanita ke luar negeri sudah menjadi hal yang sangat diminati oleh wanita di kabupaten Lombok Timur, walaupun dampak sosial yang nantinya akan dihadapi tidak membuat surut keinginan mereka untuk bermigrasi ke luar negeri. Hal tersebut terjadi karena desakan ekonomi keluarga yang menyebabkan dikirimnya anggota keluarga wanita untuk menjadi tenaga kerja ke luar negeri. Sejak dikeluarkan moratorium penghentian pengiriman tenaga kerja wanita ke Saudi Arabia, negara tujuan utama para tenaga kerja wanita migran adalah Malaysia. Pada tahun 2016 jumlah tenaga kerja Indonesia dengan negara tujuan Malaysia sebesar $95,46 \%$ dan sisanya di negara-negara lain (BPS, 2017). Untuk tenaga kerja wanita, bidang pekerjaan yang mereka jalani adalah sebagian besar bekerja sebagai pembantu rumah tanggal (PRT). Motivasi para tenaga kerja wanita tersebut sebagian besar untuk memenuhi kebutuhan rumah tangga mereka, tidak jarang juga untuk membayar hutang. Tetapi sebagian besar uang pendapatan yang dikirim kepada anggota keluarga hanya cukup untuk ememnuhi kebutuhan hidup keluarga di daerah asal. Berdasarkan permasalahan di atas maka permasalahan yang akan diangkat adalah:

1. Bagaimanakah alokasi pendapatan yang dikirim oleh tenaga kerja wanita migran kepada keluarganya dan faktor apa saja yang mempengaruhi?

2. Faktor apa saja yang mempengaruhi pengeluaran pendapatan keluarga tenaga kerja wanita migran?

\section{Tujuan penelitian}

1. Untuk mengetahui bagaimanakah alokasi pendapatan yang dikirim oleh tenaga kerja wanita migran kepada keluarganya.

2. Untuk mengetahui faktor-faktor yang mempengaruhi pengeluaran pendapatan keluarga tenaga kerja wanita migran.

\section{Batasan Masalah}

Tenaga kerja wanita migran mempunyai cakupan dan makna yang luas, maka perlu dilakukan pembatasan masalah di dalam penelitian ini adalah tenaga kerja wanita migran yang dimaksud adalah tenaga kerja yang status perkawinannya 


\section{Elastisitas - Jurnal Ekonomi Pembangunan \\ Vol. 1 No. 1, (2019), 67 - 78}

telah menikah/janda yang masih berada di luar negeri ataupun sudah kembali ke kabupatan Lombok Timur.

\section{Tinjauan Teoritis}

Teori dasar mengenai penawaran tenaga kerja bagi ibu rumah tangga didasarkan pada teori Becker pada tahun 1967 yaitu Teori New Household Economics yang kemudian dikembangkan menjadi teori Nilai Anak dan teori Alokasi Waktu. Di dalam teori New Household Economics mengasumsikan bahwa setiap individu bertindak selaku produsen sekaligus konsumen. Selain itu barangbarang seperti meja, kursi serta barang lainnya yang dijual di pasar bukanlah merupakan barang akhir (final good) Barang-barang tersebut tidak dapat langsung di konsumsi, tetapi masih perlu di olah terlebih dahulu dan dikombinasikan dengan berbagai input lainnya, dan hasil akhirnya adalah nilai kepuasan yang diperoleh individu ataupun kesejahteraan yang dinikmati anggota keluarga (Ashworth, 1991). Pada dasarnya teori New Household Economic melengkapi teori Konsumen Tradisional di dalam menginterprestasikan perilaku konsumen dan khususnya perilaku rumah tangga. Teori ini disebut juga model alternatif yang tetap merupakan perilaku konsumen dari model Neoklasik (Mattila, 1999).

Pokok permasalahan teori New Household Economics secara deskriptif berkaitan dengan teori perilaku rumah tangga. Aplikasi perilaku rumah tangga diasumsikan untuk memaksimumkan utilitasnya. Adapun utilitas maksimum tersebut dapat di analisis berdasarkan konsumsi rumah tangga/individu terhadap suatu komoditas barang dan jasa. Ironmonger (1993) dalam penelitiannya mengenai Model Ekonomi Rumah Tangga menyebutkan bahwa ekonomi rumah tangga dapat diartikan sebagai suatu sistem dari prosedur dan alokasi waktu antara pasar produksi, rumah tangga produksi, dan kesenangan. Rumah tangga mengalokasikan uang antara pembelian dari komoditi kesenangan dan pembelian barang-barang untuk produksi rumah tangga. Rumah tangga juga membuat keputusan mengenai penerimaan atau pembagian dari aset-aset riil dan keuangan.

Becker membedakan antara biaya pemeliharaan anak (seperti makan, minum, pakaian, pendidikan, kesehatan, dan lainnya) dengan kualitas anak, dengan asumsi kualitas anak diharapkan oleh orang tua. Studi yang dilakukan oleh Hoddinott (1994) dan De la Brière, et al.(2002) menunjukkan bahwa kiriman uang dimaksudkan sebagai investasi untuk warisan di masa depan. Mereka menyimpulkan bahwa jaminan hari tua adalah motif utama pengiriman uang oleh tenaga kerja wanita. Hasil ini sejalan dengan temuan dari studi tentang dukungan keuangan kepada orang tua yang dilakukan di Taiwan (Cina), yang menunjukkan bahwa anak perempuan merespon kebutuhan khusus orang tua daripada kebutuhan biasa dan berfungsi sebagai tabungan untuk keperluan mendadak, sementara hal ini tidak berlaku untuk anak laki-laki migran (Lee, et al. 1994). Sebuah studi oleh Vanwey (2004) yang menyelidiki perbedaan gender dalam motif remittance di Thailand. Dia menyimpulkan bahwa pengiriman uang oleh perempuan lebih dimotivasi oleh altruisme daripada laki-laki.

Selain motivasi pengiriman uang, laki-laki dan wanita juga berpotensi memiliki preferensi yang berbeda tentang jenis pengeluaran yang digunakan dari uang yang dikirim kepada keluarganya. Dalam studinya di Meksiko, de La Cruz (1995) menemukan bahwa migran laki-laki cenderung berniat untuk kembali ke negaranya untuk hidup secara permanen di masa depan, karena alasan ini, uang yang mereka kirim diarahkan untuk investasi pribadi seperti tanah, perumahan, produksi pertanian, dan ternak. Wanita migran juga mengirimkan untuk tujuan investasi, tetapi investasi mereka lebih ditujukan untuk pendidikan dan bisnis keluarganya daripada investasi pendidikan dan bisnis pribadinya. 


\section{Elastisitas - Jurnal Ekonomi Pembangunan \\ Vol. 1 No. 1, (2019), 67 - 78}

Studi deskriptif yang dilakukan oleh International Organisation for Migration (IOM), menggunakan data dari Moldova, menemukan bahwa lebih banyak wanita dibandingkan laki-laki migran yang mengirimkan uangnya untuk membiayai biaya pendidikan, kesehatan, peralatan rumah tangga dan pinjaman. Tenaga Kerja migran perempuan di Moldova cenderung mengirimkan uang mereka kepada keluarganya untuk kebutuhan makanan, pakaian, dan peralatan rumah tangga serta kebutuhan-kebutuhan khusus keluarga seperti pendidikan, kesehatan, dan pinjaman. Sedangkan migran laki-laki lebih memilih untuk mengarahkan pengiriman uang mereka untuk investasi jangka panjang seperti untuk perumahan, mobil dan barang-barang konsumsi (IOM 2005). Studi yang dilakukan oleh Pfeiffer dan Taylor (2002) menemukan bahwa rumah tangga yang menerima remittance dari tenaga kerja wanita memiliki pola pengeluaran yang berbeda dari mereka yang menerima remitan dari tenaga kerja laki-laki.

Di dalam kaitannya dengan tenaga kerja wanita migran, perspektif gender merupakan pembagian kerja antara lakilaki dan perempuan yang berbeda dari satu tempat ke tempat lain menurut nilai budaya masing-masing. Moser (1993) bahwa gender adalah suatu sifat yang melekat pada kaum laki-laki maupun kaum perempuan yang dikonstruksi secara sosial maupun kultural. Pembagian kerja antar keduanya bisa dipertukarkan misalnya dalam mencari nafkah untuk keluarga, jika sebelumnya mencari nafkah dilakukan oleh laki-laki boleh di tukar dan dikerjakan oleh wanita. Peningkatan keterlibatan wanita di sektor produktif ini disebabkan oleh proses yang saling berkaitan, yang menyangkut pergeseran dalam diri wanita sendiri dalam sistem nilai dan normatif yang menyangkut perubahan dalam kelembagaan. Sebagian besar wanita bekerja karena ekonomi rumah tangga menuntut agar mereka ikut berperan di dalam memenuhi kebutuhan rumah tangga atau keluarga, sedangkan sebagian lagi bekerja untuk memenuhi kebutuhan diri sendiri. Schampers dan Speckman (1992) menyebutkan bahwa aktivitas wanita tangga berhubungan dengan bekerja ke luar rumah atau masuk ke dalam pasar tenaga kerja terutama di negara berkembang merupakan strategi rumah tangga untuk mempertahankan kelangsungan hidupnya yang penuh dengan tantangan dan rentan terhadap kekerasan.

Teori nurture menyebutkan adanya perbedaan perempuan dan laki-laki pada hakikatnya adalah hasil konstruksi sosial budaya sehingga menghasilkan peran dan tugas yang berbeda. Sedangkan menurut teori nature, adanya perbedaan perempuan dan laki-laki adalah karena kodrat yang menyebabkan perbedaan biologis yang memberikan implikasi bahwa kedua jenis tersebut memiliki peran dan tugas yang berbeda.

\section{Metode Penelitian}

Penelitian ini menggunakan penelitian kuantitatif, dengan lokasi penelitian dilakukan di Kabupaten Lombok Timur dengan mengambil sebanyak 5 kecamatan dari jumlah 20 kecamatan yang ada di kabupaten tersebut. Kecamatankecamatan yang ditentukan adalah berdasarkan pertimbangan jumlah tenga kerja wanita yang dimiliki. Adapun kecamatan-kecamatan yang di maksud meliputi Kecamatan Terara, Kecamatan Aikmel, Kecamatan Pringgabaya, Kecamatan Sakra Barat, dan Kecamatan Keruak. Dengan mengambil sebanyak 5 (lima) sampel kecamatan tersebut, disebabkan karena Kabupaten Lombok Timur mempunyai wilayah yang luas. Untuk menentukan ukuran sampel, populasi menggunakan jumlah tenaga kerja di Kabupaten Lombok Timur pada tahun 2017 sejumlah 1.332 orang, berdasarkan data BPS tahun 2018.

Dari keseluruhan populasi, jumlah sampel yang diambil adalah sebanyak 50 orang. Kemudian berdasarkan 5 (lima) kecamatan yang menjadi lokasi penelitian ditentukan desa-desa tempat pengambilan 


\section{Elastisitas - Jurnal Ekonomi Pembangunan \\ Vol. 1 No. 1, (2019), 67 - 78}

sampel. Sampel yang di ambil pada tiap desa dihitung berdasarkan rasio dari jumlah tenaga kerja wanita pada masing-masing desa yang terpilih menjadi desa sampel. Metode pengambilan sampel lokasi yang digunakan adalah metode Purposive Sampling yaitu teknik pengambilan sampel yang di sengaja. Jumlah sampel ditentukan sebanyak 5 kecamatan terbesar yang menjadi basis TKW dan diambil 3 desa di kecamatan tersebut. Pengambilan responden sesuai dengan proporsi jumlah TKW masing -masing desa yang meliputi anggota keluarga tenaga kerja wanita dan tenaga kerja wanita yang baru kembali ke daerah asal. Cara pengambilan sampel lokasi ini dilakukan dengan pertimbangan dapat mewakili responden dari desa-desa yang ada di kabupaten tersebut. Selain itu juga dengan pertimbangan efisiensi waktu dan biaya serta tenaga, agar dapat lebih memudahkan pelaksanaan penelitian.

Untuk menganalisis alokasi pendapatan keluarga dari remittance yang diterima, menggunakan analisis model Seemingly Unrelated Regression (SUR) yang beberapa variabelnya mengikuti penelitian sebelumnya yang dilakukan oleh Adam, Jr dan Cuecuecha (2010) yang menggunakan model logit sebagai alat analisisnya. Model analisis Seemingly Unrelated Regression (SUR) adalah sebagai berikut:
a. $\mathrm{MKN}=b_{11}+b_{12} \mathrm{AL} \_\mathrm{MKN}+$ $b_{13} B B_{M K N}+b_{14} B A_{-} M K N+\varepsilon_{1}$
b. $\mathrm{PDD}=b_{21}+b_{22} \mathrm{AL} \_\mathrm{PDD}+$ $b_{23} B B_{-} P D D+b_{24} B A \_P D D+\varepsilon_{2}$
c. $\mathrm{KRT}=b_{31}+b_{32} \mathrm{AL} \_\mathrm{KRT}+$ $b_{33} B B_{-} K R T+b_{34} B A_{-} K R T+\varepsilon_{3}$
d. $\mathrm{KHT}=b_{41}+b_{42} \mathrm{AL} \_\mathrm{KHT}+$ $b_{43} B B_{-} K H T+b_{44} B A \_K H T+\varepsilon_{4}$

Pengertian variabel-variabel bebas dapat dijelaskan sebagai berikut :

1. Pengeluaran keluarga Tenaga Kerja Wanita migran yang terdiri dari: a. MKN adalah pengeluaran makanan yaitu jumlah uang yang dibelanjakan untuk makanan oleh keluarga tenaga kerja wanita selama satu bulan dalam satuan rupiah.

b. PDD adalah pengeluaran pendidikan yaitu jumlah biaya yang dikeluarkan oleh keluarga tenaga kerja wanita untuk biaya pendidikan anak/anggota keluarga yang ditanggung selama satu bulan dalam satuan rupiah

c. KRT adalah kebutuhan rumah tangga, yaitu jumlah biaya yang dikeluarkan oleh keluarga untuk kebutuhan rumah tangga berupa kebutuhan non makanan selama satu bulan dalam satuan rupiah.

d. KHT adalah kesehatan, yaitu biaya yang dikeluarkan oleh keluarga tenaga kerja wanita untuk biaya kesehatan seluruh anggota keluarga dalam satuan rupiah.

2. AL adalah anggota keluarga, yaitu jumlah anggota keluarga yang tinggal satu rumah dengan tenaga kerja wanita, yang terdiri dari orang tua (ibu dan bapak), suami, anak dan saudara.

3. BA adalah jumlah anak, yaitu jumlah anak tenaga kerja wanita usia di atas 618 tahun.

4. BB adalah jumlah anak, yaitu jumlah anak tenaga kerja wanita usia di bawah 5 tahun.

\section{Hasil dan pembahasan \\ Alokasi Pendapatan Rumah Tangga Tenaga Kerja Wanita Migran}

Remiten yang dikirim oleh TKW migran untuk keluarga mereka digunakan untuk memenuhi kebutuhan hidup keluarga. Adapun alokasi pengeluaran rumah tangga TKW migran per bulan untuk kebutuhan makanan, pedidikan, kebutuhan rumah tangga lainnya dan kesehatan dapat dilihat pada tabel berikut.

Tabel 1

Alokasi Pengeluaran Rata- Rata Rumah Tangga TKW Migran per bulan 


\section{Elastisitas - Jurnal Ekonomi Pembangunan \\ Vol. 1 No. 1, (2019), 67 - 78}

\begin{tabular}{|c|c|c|c|}
\hline No. & $\begin{array}{c}\text { Alokasi Pengeluaran Rumah } \\
\text { Tangga }\end{array}$ & $\begin{array}{c}\text { Jumlah Rata-Rata } \\
\text { Pengeluaran Per } \\
\text { Bulan }\end{array}$ & Proporsi (\%) \\
\hline 1. & Makanan & Rp. 871.000,- & 62 \\
\hline 2. & Pendidikan & Rp. 103.000,- & 8 \\
\hline 3. & $\begin{array}{c}\text { Kebutuhan Rumah Tangga } \\
\text { Lainnya }\end{array}$ & Rp. 339.200,- & 25 \\
\hline 4. & Kesehatan & Rp. 70.100,- & 5 \\
\hline & Jumlah & Rp.1.383.000,- & $100 \%$ \\
\hline
\end{tabular}

Sumber: Data Primer Diolah, 2018

Dari tabel di atas dapat dilihat bahwa alokasi pengeluaran makanan mempunyai proporsi yang paling tinggi sebesar $62 \%$ yaitu Rp. 871.000,- . Selanjutnya diikuti oleh pengeluaran kebutuhan rumah tangga lainnya berupa kebutuhan sandang sebesar $8 \%$, pengeluaran pendidikan berupa buku, alat tulis dan lainnya yang berkaitan dengan pedidikan sebesar $8 \%$ dan pengeluaran kesehatan sebesar 5\% dari total pengeluaran rata-rata keluarga TKW migran per bulannya.
Alokasi Pendapatan Untuk pengeluaran
Makanan dan faktor Yang
Mempengaruhinya.
Dari hasil analisis untuk melihat faktor-faktor yang mempengaruhi pengeluaran keluarga TKW migran dari remiten yang dikirim dapat dilihat dengan menggunakan analisis Seemingly Unrelated Regression (SUR) pada tabel tabel berikut ini:

Tabel 2

Variabel Dependen Pengeluaran Makanan (MKN)

\begin{tabular}{|c|c|c|}
\hline \multirow{2}{*}{ Variabel Independen } & \multicolumn{2}{|c|}{ Makanan (MKN) } \\
\cline { 2 - 3 } & Koefisien & Signifikan \\
\hline Jumlah Tanggungan keluarga (AL) & 107045.5 & 0.122 \\
\hline Usia Anak 6-18 tahun (BA) & 314263 & $0.000^{*}$ \\
\hline Usia anak 0-5 tahun (BB) & 452627.9 & $0.000^{*}$ \\
\hline Konstanta & 89583.94 & 0.649 \\
\hline
\end{tabular}

Keterangan: *Signifikan pada tingkat 5\%

Sumber: Data primer, diolah 2018

$$
\begin{aligned}
\mathrm{MKN}= & 89583.94+107045.5 \mathrm{AL} \_\mathrm{MKN}+ \\
& \text { 314263 BA_MKN }+452627.9 \\
& \text { BB_MKN+ } \varepsilon
\end{aligned}
$$

Pada hasil analisis, pengeluaran rumah tangga (KRT) dari remiten yang dikirimkan oleh TKW migran dialokasikan paling besar untuk kebutuhan makanan (MKN) sebesar $62 \%$ atau Rp.871.000,rata-rata per bulan. Alokasi pendapatan untuk pengeluaran makanan (MKN) ini berpengaruh signifikan terhadap jumlah anak usia 6-18 tahun (BA) dan anak usia 05 tahun (BB). Hal tersebut dapat ditunjukkan pada nilai koefisien anak usia 6-18 tahun (BA) sebesar 314263 dengan probabilitas 0.000 pada tingkat signifikansi $5 \%$. Yang artinya bahwa setiap kenaikan jumlah anak usia 6-18 tahun banyak 1 orang maka akan meningkatkan jumlah pengeluaran makanan sebesar Rp. 314.263,- setiap bulannya. Demikian juga anak usia 0-5 tahun berpengaruh positif dan signifikan terhadap pengeluaran makanan dengan nilai koefisien 452627.9 dengan nilai probabilitas 0.000 dengan tingkat signifikansi sebesar 5\%. Yang artinya bahwa kenaikan jumah usia anak 0-5 tahun sebesar 1 orang akan meningkatkan jumlah pengeluaran makanan sebesar Rp. 452.627.9,- per bulan. Hal tersebut disebabkan karena anak usia 6-18 tahun dan 


\section{Elastisitas - Jurnal Ekonomi Pembangunan \\ Vol. 1 No. 1, (2019), 67 - 78}

anak usia 0-5 tahun mempunyai kebutuhan makanan lebih tinggi dari orang dewasa.

Hasil penelitian ini sesuai dengan penelitian yang dilakukan oleh International Organisation for Migration (IOM), dengan menggunakan data dari Moldova, ditemukan bahwa lebih banyak wanita dibandingkan laki-laki migran yang mengirimkan uangnya untuk membiayai biaya pendidikan, kesehatan, peralatan rumah tangga dan pinjaman. Tenaga Kerja migran perempuan di Moldova cenderung mengirimkan uang mereka kepada keluarganya untuk kebutuhan makanan, pakaian, dan peralatan rumah tangga serta kebutuhan-kebutuhan khusus keluarga seperti pendidikan, kesehatan, dan pinjaman. Sedangkan migran laki-laki lebih memilih untuk mengarahkan pengiriman uang mereka untuk investasi jangka panjang seperti untuk perumahan, mobil dan barang-barang konsumsi (IOM 2005).

\section{Alokasi Pendapatan Untuk pengeluaran Pendidikan dan faktor Yang Mempengaruhinya.}

Tabel 3

Variabel Dependen Pengeluran Pendidikan (PDD)

\begin{tabular}{|c|c|c|}
\hline \multirow{2}{*}{ Variabel Independen } & \multicolumn{2}{|c|}{ Pendidikan } \\
\cline { 2 - 3 } & Koefisien & Signifikan \\
\hline Jumlah Tanggungan keluarga (AL) & 5468.118 & 0.745 \\
\hline Usia Anak 6-21 tahun (BA) & 50691.26 & $0.015^{*}$ \\
\hline Usia anak 0-5 tahun (BB) & -16854.25 & 0.591 \\
\hline Konstanta & 16799.92 & 0.725 \\
\hline
\end{tabular}

Keterangan: *Signifikan pada tingkat 5\%

Sumber: Data primer, diolah 2018

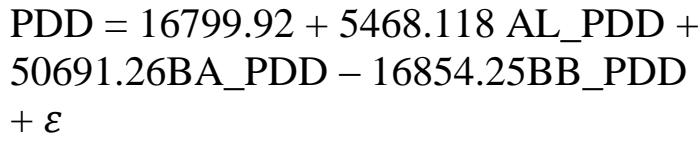

Dari hasil analisis data alokasi pendapatan untuk pengeluaran pendidikan (PDD) adalah sebesar 8\% dari jumlah keseluruhan rata-rata pengeluaran keluarga TKW migran atau sebesar Rp. 103.000,rata-rata per bulan. Dari hasil analisis diketahui bahwa alokasi pendapatan untuk pengeluaran pendidikan (PDD) tersebut berpengaruh positif dan signifikan terhadap anak usia 6-18 tahun (BA). Nilai koefisien yang didapat adalah sebesar 50691.26 dengan probabilitas sebesar 0.015 dengan tingkat signifikansi 5\%. Artinya bahwa setiap kenaikan jumlah anak usia 6-18 tahun (BA) akan meningkatkan jumlah pengeluaran pendidikan sebesar $\mathrm{Rp}$. 50.691.26,-- per bulan. Hasil penelitian ini sesuai dengan penelitian De La Cruz (1995) dalam studinya di Mexico menemukan bahwa migran laki-laki cenderung berniat untuk kembali ke negaranya untuk hidup secara permanen di masa depan, karena alasan ini, uang yang mereka kirim diarahkan untuk investasi pribadi seperti tanah, perumahan, produksi pertanian, dan ternak. Wanita migran juga mengirimkan untuk tujuan investasi, tetapi investasi mereka lebih ditujukan untuk pendidikan dan bisnis keluarganya daripada investasi pendidikan dan bisnis pribadinya. Quisumbing dan Maluccio (2000), menggunakan data dari Bangladesh, Ethiopia, Indonesia, dan Afrika Selatan, menyimpulkan bahwa efek yang paling konsisten di negara-negara tersebut adalah persentase peningkatan sumber daya dikendalikan oleh wanita pada saat pernikahan adalah peningkatan jumlah pengeluaran untuk pendidikan. Temuan ini berlaku untuk semua negara kecuali untuk Ethiopia.

Tetapi hasil penelitian ini tidak sejalan dengan studi yang dilakukan oleh Pfeiffer dan Taylor (2002) menemukan bahwa rumah tangga yang menerima remittance dari tenaga kerja wanita memiliki pola pengeluaran yang berbeda dari mereka yang menerima remittance dari 


\section{Elastisitas - Jurnal Ekonomi Pembangunan \\ Vol. 1 No. 1, (2019), 67 - 78}

tenaga kerja laki-laki. Rumah tangga yang menerima remittance dari tenaga kerja wanita mengalokasikan porsi pengeluaran yang lebih besar untuk kesehatan dan barang-barang lainnya, dan bagian yang lebih kecil untuk makanan. Hal ini menunjukkan bahwa rumah tangga yang menerima remittance dari istri mengalokasikan jauh lebih sedikit untuk pendidikan dibandingkan rumah tangga yang menerima remittance dari suami. Ada 2 (dua) alasan yang bisa menjelaskan hal ini. Pertama, pria cenderung menghabiskan lebih sedikit uang untuk pendidikan dibandingkan wanita, sehingga rumah tangga di mana istri tidak ada cenderung mengeluarkan lebih sedikit untuk pendidikan. Kedua, ketika istri meninggalkan rumah tangga, adalah lazimnya dilakukan setelah anak-anak mereka tamat sekolah, sehingga mengakibatkan sebagian kecil dari total pengeluaran dialokasikan untuk pendidikan pada rumah tangga yang ditinggalkan. Lu dan Theiman (2007) melakukan penelitian mengenai pengaruh remiten yang dikirim terhadap partisipasi sekolah anak. Hasilnya menunjukkan bahwa dengan adanya

Tabel 4

Variabel Dependen Pengeluaran Kebutuhan Rumah tangga Lainnya (KRT)

\begin{tabular}{|c|c|c|}
\hline \multirow{2}{*}{ Variabel Independen } & \multicolumn{2}{|c|}{$\begin{array}{c}\text { Pengeluaran Kebutuhan Rumah Tangga } \\
\text { Lainnya }\end{array}$} \\
\cline { 2 - 3 } & Koefisien & Signifikan \\
\hline Jumlah Tanggungan keluarga & 86005.3 & 0.002 \\
\hline (AL) & & 0.755 \\
\hline Usia Anak 6-21 tahun (BA) & -10992.93 & 0.191 \\
\hline Usia anak 0-5 tahun (BB) & -69150.22 & 0.583 \\
\hline Konstanta & 44148.29 & \\
\hline
\end{tabular}

Keterangan: *Signifikan pada tingkat 5\%

Sumber: Data primer, diolah 2018

$\mathrm{KRT}=44148.29+86005.3 \mathrm{AL} \_\mathrm{KRT}-$ 10992.93 BA_KRT - 69150.22 BB_KRT $+\varepsilon$

Hasil analisis data alokasi pendapatan untuk pengeluaran kebutuhan rumah tangga lainnya (KRT) adalah sebesar $25 \%$ dari jumlah keseluruhan pengeluaran rumah tangga TKW migran atau sejumlah remiten yang dikrim dapat meningkatkan pengeluaran pendidikan.

Perbedaan dari hasil penelitian terdahulu ini disebabkan oleh kultur budaya dari masing-masing obyek penelitian berbeda, sehingga pola pikir dan cara pandang setiap individu diberbagi wilayah pun dapat berbeda. Hal tersebut dapat ditinjau dari Teori Nurture yang menyebutkan adanya perbedaan perempuan dan laki-laki pada hakikatnya adalah hasil konstruksi sosial budaya sehingga menghasilkan peran dan tugas yang berbeda. Schampers dan Speckman (1992) menyebutkan bahwa aktivitas wanita tangga berhubungan dengan bekerja ke luar rumah atau masuk ke dalam pasar tenaga kerja terutama di negara berkembang merupakan strategi rumah tangga untuk mempertahankan kelangsungan hidupnya yang penuh dengan tantangan dan rentan terhadap kekerasan.

\section{Alokasi Pendapatan Untuk pengeluaran Kebutuhan Rumah Tangga Lainnya dan faktor Yang Mempengaruhinya.}




\section{Elastisitas - Jurnal Ekonomi Pembangunan \\ Vol. 1 No. 1, (2019), 67 - 78}

sebesar 86005.3 dengan tingkat probabilitas 0.002 dengan tingkat signifikan sebesar 5\%. Artinya bahwa jika jumlah anggota keluarga (AL) meningkat sejumlah 1 orang maka akan meningkatkan jumlah pengeluran kebutuhan rumah tangga lainnya (KRT) sebesar Rp. 86.005.3,- rata-rata per bulan.

Dalam pemahaman The New Household Economic dalam Teori Alokasi Waktu, jika dikaitkan dengan pemenuhan terhadap barang yang bukan merupakan kebutuhan makanan sehari-hari. Terdapat pembedaan biaya pemeliharaan anak dengan kualitas anak tersebut dengan harapan dari biaya pemeliharaan yang telah dikeluarkan akan menghasilkan kualitas anak seperti yang diharapkan orang tuanya. Selain hal tersebut terdapat pembedaan antara biaya pemeliharaan anak (makan, minum, pakaian, pendidikan, kesehatan dan lain sebagainya) dengan kualitas anak, dalam asumsi kualitas anak yang diharapkan oleh orang tuanya.

\section{Alokasi Pendapatan Untuk pengeluaran Kesehatan dan faktor Yang Mempengaruhinya.}

\section{Tabel 5}

Variabel Dependen Pengeluaran Kesehatan (KHT)

\begin{tabular}{|c|c|c|}
\hline \multirow{2}{*}{ Variabel Independen } & \multicolumn{2}{|c|}{ Kesehatan } \\
\cline { 2 - 3 } & Koefisien & Signifikan \\
\hline Jumlah Tanggungan keluarga \\
(AL) & 48798.98 & 0.000 \\
\hline Usia Anak 6-21 tahun (BA) & 8191.338 & 0.546 \\
\hline Usia anak 0-5 tahun (BB) & 39675.66 & 0.051 \\
\hline Konstanta & -4142.445 & 0.894 \\
\hline
\end{tabular}

Keterangan: *Signifikan pada tingkat 5\%

Sumber: Data primer, diolah 2018

$\mathrm{KHT}=-4142.445+48798.98 \mathrm{AL} \_\mathrm{KHT}+$ 8191.338 BA_KHT +39675.66 BB_KHT+ $\varepsilon$

Hasil analisis data alokasi pendapatan TKW migran untuk pengeluaran kesehatan adalah sebesar $5 \%$ dari jumlah keseluruhan pengeluaran rumah tangga atau sebesar Rp. 70.100,rata-rata per bulan. Untuk hasil analisis faktor yang mempengaruhi pengeluaran kesehatan dapat diketahui bahwa jumlah tanggungan keluarg (AL) dan jumlah anak usia 0-5 tahun mempunyai hubungan positif dan signifikan terhadap pengeluaran kesehatan. Hal tersebut dapat dilihat dar nilai masing-masing koefisien, yaitu jumlah anggota keluarga (AL) mempunyai nilai koefisien sebesar 48798.98 dengan tingkat probabilitas sebesar 0.000 dengan tingkat signifikan sebesar 5\%. Artinya setiap kenaikan jumlah anggota keluarga (AL) sebanyak 1 orang maka akan meningkatkan jumlah pengeluaran kesehatan sebesar Rp. 48.798.98,- ratarata per bulan. Sedangkan nilai koefisien jumlah anak usia 0-5 tahun (BB) sebesar 39675.22 dengan probabilitas sebesar 0.051 dengan tingkat signifikan sebesar 5\%. Artinya bahwa setiap kenaikan jumlah anak usia 0-5 tahun sebanyak 1 orang maka akan meningkatkan jumlah pengeluaran kesehatan sebesar Rp. 39.675.66,- rata-rata per bulan. Secara logika hal tersebut dapat terjadi disebabkan karena pengeluaran kesehatan tergantung dari jumlah anggota keluarga yang ditanggung, selain itu anak usia 0-5 tahun masih membutuhkan perawatan kesehatan yang lebih intensif untuk pertumbuhan dan kecukupan gizi sesuai dengan usia. Studi yang dilakukan oleh Pfeiffer dan Taylor (2002) menemukan bahwa rumah tangga yang menerima remiten dari tenaga kerja wanita memiliki pola 


\section{Elastisitas - Jurnal Ekonomi Pembangunan \\ Vol. 1 No. 1, (2019), 67 - 78}

pengeluaran yang berbeda dari mereka yang menerima remiten dari tenaga kerja laki-laki. Rumah tangga yang menerima remiten dari tenaga kerja wanita mengalokasikan porsi pengeluaran yang lebih besar untuk kesehatan dan barang-barang lainnya, dan bagian yang lebih kecil untuk makanan. Survei Demografi dan Kesehatan yang dilakukan Smith dan Byron (2005) di Bangladesh, India, Nepal, dan Pakistan, menyimpulkan bahwa peningkatan kekuasaan pengambilan keputusan oleh perempuan relatif terhadap laki-laki sangat terkait dengan peningkatan gizi dan kesejahteraan anak.

\section{Kesimpulan dan saran \\ Kesimpulan}

1. Alokasi pendapatan keluarga tenaga kerja wanita yang bermigrasi ke luar negeri adalah sebagai berikut:

a. Alokasi untuk pengeluaran makanan sejumlah Rp. 871.000,- atau sebesar 62 persen rata-rata per bulan.

b. Alokasi untuk pengeluaran pendidikan sejumlah Rp. 103.000,- atau sebesar 8 persen rata-rata per bulan.

c. Alokasi untuk pengeluaran kebutuhan rumah tangga lainnya sejumlah $\mathrm{Rp}$. 339.200 atau sebesar 25 persen ratarata per bulan.

d. Alokasi untuk pengeluaran kesehatan sejumlah Rp.70.100,- sebesar 5 persen rata-rata per bulan.

2. Faktor-faktor yang mempengaruhi pengeluaran pendapatan keluarga TKW migran adalah sebagai berikut:

a. Faktor yang mempengaruhi pengeluaran makanan adalah jumlah anak usia 6-18 tahun dan jumlah anak usia 0-5 tahun. Dimana jumlah pengeluaran makanan akan bertambah ssejumlah Rp 314.263,- dan Rp.452.627.9,- jika jumlah anak usia 6-18 tahun dan jumlah anak usia 0-5 tahun bertambah masing-masing 1 orang. b. Faktor yang mempengaruhi pengeluaran pendidikan adalah jumlah anak usia 6-18 tahun. Dimana setiap kenaikan jumlah anak usia 6-18 tahun sebanyak 1 orang akan meningkatkan jumlah pengeluaran pendidikan sebesar Rp.50.691.26,-

c. Faktor yang mempengaruhi jumlah pengeluaran kebutuhan rumah tangga lainnya adalah jumlah tanggungan keluarga. Dimana jika jumlah tanggungan keluarga bertambah 1 orang maka akan meningkatkan jumlah pengeluaran kebutuhan rumah tangga lainnya sebesar Rp. 86.005.3,-.

d. Faktor yang mempengaruhi pengeluaran kesehatan adalah jumlah tanggungan keluarga dan jumlah anak usia 0-5 tahun. Dimana jika jumlah tanggungan keluarga dan jumlah amak usia 0-5 tahun bertambah sebanyak masing-masing 1 orang maka akan meningkatkan jumlah pengeluaran kesehatan masing-masing sebesar Rp 48.789,98,- untuk jumlah tanggungan keluarga dan sebesar Rp. 39.675.66 untuk jumlah anak usia 0-5 tahun.

\section{Saran}

1. Secara umum TKW mampu meningkatkan kondisi ekonomi keluarga, tetapi di sisi lain mereka hanya bekerja sebagai pembantu rumah tangga yang tidak terlalu menuntut keahlian yang spesifik. Oleh sebab itu perlu dipersiapkan tingkat keahlian yang lebih baik bagi para TKW oleh pemerintah maupun penyedia jasa TKW melalui program peningkatan kompetensi keahlian bagi para calon TKW. Program tersebut dapat dilakukan melalui kegiatan pelatihan bahasa, pelatihan cara memasak sesuai dengan negara tujuan, pelatihan cara menggunakan alat-alat elektronik untuk rumah tangga, pelatihan yang berkaitan dengan etika.

2. Perlunya dilakukan edukasi bagi para tenaga kerja wanita yang bermigrasi ke 


\section{Elastisitas - Jurnal Ekonomi Pembangunan \\ Vol. 1 No. 1, (2019), 67 - 78}

luar negeri, bahwa motivasi untuk mereka bekerja di luar negeri tidak hanya untuk memenuhi kebutuhan rumah tangga saja. Tetapi perlunya alokasi investasi untuk anak di masa yang akan dating dengan menabung sebagian dari pendapatan untuk pendidikan anak-anak di masa yang akan dating.

\section{Daftar Pustaka}

Acosta, Pablo. (2007). Entrepreneurship, Labor Market, and International Remittances: Evidence from El Salvador. In Ozden and M. Schiff (eds). International Migration. Economic Development \& Policy (World Bank and Palgrave Macmillan: 141-159.

Adam, H, R, Jr, . Cuecuencha, A. 2010. The Economic Impact of International Remittances on Proverty and Household Consumption and Investment in Indonesia. Policy Research Working Paper. 5433.

Ashworth, J. S and D. T. Ulph. 1991. Household Models. In C.V. Brown, ed. Taxation and Labour Supply. London: Allen and Unwin.

Bahns, Karin Margareth. 2005, Rural to Urban Migration in Developing Countries: Applicability the HarrisTodaro Model with Special Focus on Chinese Economy. Konstanz University.

Badan Pusat Statistik. 2017. NTB Dalam Angka 2017. Mataram.

Badan Pusat Statistik. 2017. Kabupaten Lombok Timur Dalam Angka 2017 Lombok Timur.

Bardhan, P., Urdy, K. 1999. Development Microeconomics. Oxford University Press. New York.

Bryant,J. 2005. Children of International Migrants in Indonesia, Thailand, and the Philippines: A review of Evidence and Policies. Pdf. in www.unicef.org/irc.

Becker, S. G. 1965. A Theory of Allocation of Time. The Economics Journal. 75 (299): 493-517.

De la Brière, Bénédicte, Alain de Janvry, Elisabeth Sadoulet, and Sylvie Lambert. 2002. The Roles of Destination, Gender, and Household Composition in Explaining Remittances: An Analysis for the Dominican Sierra. Journal of Development Economics. 68 (2): 30928.

De la Cruz, Blanca E. 1995. "The Socioeconomic Dimensions of Remittances: A Case Study of Five Mexican Families." Berkeley McNair Journal. 3: 1-10.

Hoddinott, John. 1994. A Model of Migration and Remittances Applied to Western Kenya. Oxford Economic Papers. 46 (3): 459-76.

Hugo, G. 1995. Labor Export From Indonesia: An Overview. ASEAN Economic Bulletin. 12 (2).

IOM. 2004. International Migration Law: Glossary on Migration. International Organization for Migration.

2005. Migration and Remittances in Moldova. Moldova: IOM.

Lee, Yean-Ju,William L. Parish, and Robert J.Willis. 1994. "Sons, Daughters, and Intergenerational Support in Taiwan." American Journal of Sociology. 99 (4): 10-41.

Maresova, J. 1999. Labor Migration to Austria: Czech and Slovak Temporary Workers in Vienna. IWM Junior Visiting Fellows Conferences. 8 (9).

Moser, Caroline and Moser, Annalise. 1993. Gender Mainstreaming Since Beijing: A review success and 
limitations in international institutions. Gender and Development. 2005.

Pfeiffer, R. et al. 2008. The International Migration of Women: Gender in Economic Research on International Migration and Its Impact a Critical Review. The International Bank of Reconstruction and Development/The World Bank. Washington DC.

Quartey, Peter. 2005. Shared Growth in Ghana: Do Migrant Remittances Have a Role?. Paper presented at the international conference Shared Growth in Africa. Cornell University. Institute of Statistical. Social and Economic Research (University of Ghana). The World Bank. Accra. July 21-22.

Quartey, Peter, 2006. The Impact of Migrant Remittances on Household Welfare in Ghana. AERC Research Paper 158, African Economic Research Consortium, Nairobi.
Sugiyono. 2013. Metode Penelitian Kombinasi (Mixed Methods). ALFABETA. Jakarta.

Smith, Lisa C., and Elizabeth M. Byron. 2005. Is Greater Decisionmaking Power of Women Associated with Reduced Gender Discrimination in South Asia? IFPRI Discussion Paper 200.Washington, DC: International Food Policy Research Institute.

Schampers, F Eelens and Speckman, Johan, Dirk. 1992. Labour Migration to the Middle East: from Srilanka to the Gulf. Kegan Paul intl.

Vanwey, K Leah. 2004. Altruistic and Contractual Remittances Between Male and Female Migrants and Households in Rural Thailand. Demography. 42 (4): 739-756.

Zhu, Nang. 2002. Impact of Income Gap on Migration Decision in China: A Verification of the Todaro Model. China Economic Review. 13: 213-230. 